\title{
Reestruturação da Palhaçaria no Ambiente Hospitalar de Atenção Oncológica em razão da Covid-19
}

doi: https://doi.org/10.32635/2176-9745.RBC.2021v67n4.1373

\author{
Clowning Restructuring in the Hospital Environment of Oncological Attention due to COVID-19 \\ Remodelación de la Payasada en el entorno Hospitalario de Atención Oncológica por la Covid-19
}

\section{Felipe Calderon Scarin ${ }^{1}$; Felipe Senra Santos ${ }^{2}$; Carolina de Oliveira Azim Schiller ${ }^{3}$; Cristiane Marques de Sousa ${ }^{4}$; William Augusto Gomes de Oliveira Bellani ${ }^{5}$}

\section{INTRODUÇÃO}

A hospitalização é caracterizada por perda da privacidade, limitação espacial e perda do contato social. Alto índice de estresse é deflagrado no contexto hospitalar, contribuindo para o surgimento de ansiedade e sentimentos conflituosos $^{1}$, ainda mais quando envolve pacientes diagnosticados com câncer. A complexidade decorrente do contexto hospitalar oncológico extrapola aspectos clínicos: demanda abordagens sociais, psicológicas, espirituais, econômicas e favorece a atuaçáo da interdisciplinaridade ${ }^{2}$. Esses aspectos e a necessidade de contribuir para a qualidade de vida durante a hospitalizaçáo e de facilitar o enfrentamento das adversidades ${ }^{3}$ favoreceram a ação de palhaços.

A palhaçaria surge então como forma de reinventar esse ambiente. $\mathrm{O}$ silêncio dá lugar às cançôes, a introspecção é suprimida pelas interaçóes, o choro cede espaço para o sorriso, a saúde é promovida por meio da diversãó . Busca-se oferecer uma assistência humanizada, respeito e empatia. O palhaço é capaz de alterar as relaçóes de hierarquia, redefinir os ambientes, estimular a comunicação, além de satirizar as fragilidades humanas e conceder leveza aos sentimentos mais pesados 5 . Embora muitos projetos foquem no público pediátrico, destaca-se aqui um grupo dedicado às interaçóes com os adultos: Especialistas da Alegria. A organização, fundada em 2012, traz ressignificação dos valores particulares e dos objetivos do tratamento oncológico ${ }^{6}$. Os voluntários percorrem setores hospitalares promovendo autoestima e bem-estar, além de participarem de eventos de promoção à saúde e prevenção de doenças. Conforme o relatório anual do Hospital Erasto Gaertner de 20197 , cerca de 62 mil pessoas foram atendidas pelos 26 participantes durante o ano.
Entretanto, no primeiro semestre de 2020, o grupo foi surpreendido pela pandemia da covid-19. Os riscos de contágio e o contato com pacientes imunossuprimidos resultaram na suspensão das atividades presenciais. Mas tal situação não impediu a transmissão de esperança e de bom humor às pessoas em contexto hospitalar. A readaptação da interação e a utilizaçáo dos meios digitais foram as soluçóes encontradas pelos palhaços para fortalecer o respeitável público durante a pandemia.

Desta forma, objetivou-se compreender os fatores desencadeados pela atuaçáo da ludoterapia no ambiente hospitalar, extrapolando a percepçáo para além dos enfermos, alcançando também acompanhantes, profissionais de saúde e voluntários; e enfatizar a relevância dos meios tecnológicos como coparticipantes no enfrentamento às dificuldades impostas pela pandemia na sociedade contemporânea.

\section{DESENVOLVIMENTO}

O estudo, aprovado pelo Comitê de Ética em Pesquisa, sob parecer consubstanciado $\mathrm{n}^{\circ}$. 4.087.832, CAAE: 32121120.3.3003.5225, aborda a rotina de voluntários da palhaçaria em ambiente hospitalar de atenção oncológica. O projeto acontecia presencialmente em quatro dias da semana (terça-feira à tarde, quarta-feira e quinta-feira à noite, e sábado pela manhã) com grupos de três palhaços ou mais, atingindo o público adulto, independente do gênero. Cançōes, poesias, instrumentos de percussão, técnicas de relaxamento, trocadilhos, movimentação corporal, mágicas, histórias e serenatas compunham as práticas oferecidas. Entretanto, as regras para conter a pandemia na cidade afetaram as açóes, proporcionando um novo horizonte a ser explorado pelos palhaços: a tecnologia.

\footnotetext{
1,2,4 Universidade Federal do Paraná (UFPR). Curitiba (PR), Brasil. E-mails: felipe_scarin@hotmail.com; flpsenra@gmail.com; cris.marques86@gmail.com. Orcid iD: https://orcid.org/0000-0001-6109-2138; Orcid iD: https://orcid.org/0000-0002-4547-4539; Orcid iD: https://orcid.org/0000-0003-4097-1998

${ }_{3}^{3}$ Secretaria de Estado da Saúde do Paraná (SESA)/Escola de Saúde Pública do Paraná (ESPP). Curitiba (PR), Brasil. E-mail: caroazim@hotmail.com. Orcid Id: https:// orcid.org/0000-0001-5593-4191

${ }^{5}$ UFPR. Centro Universitário UniDomBosco. Curitiba (PR), Brasil. E-mail: william.bellani@gmail.com. Orcid iD: https://orcid.org/0000-0002-1429-616X

Endereço para correspondência: Felipe Calderon Scarin. Rua Fernando Amaro, 161, apto. 5 - Alto da XV.Curitiba (PR), Brasil. CEP 80045-080. E-mail felipe_scarin@hotmail.com
} 
Os voluntários se engajaram na criação de conteúdos audiovisuais. Individualmente, iniciaram gravaçôes de vídeos repletos de brincadeiras em ambiente doméstico, com duraçấo média de quatro minutos. A maioria dos voluntários se adaptou bem ao novo formato, embora alguns não se sentissem preparados ou não tivessem facilidade com os recursos tecnológicos. No início, houve dificuldade à exposição dos vídeos em razão das restriçôes dos protocolos de segurança em ambiente hospitalar. Porém, testes com televisores foram executados e as apresentaçôes foram aceitas como adaptação para tal período. Equipes de enfermagem do hospital fizeram o intercâmbio entre o grupo Especialistas da Alegria e os hospitalizados, apresentando os conteúdos produzidos nos televisores dos quartos e das áreas sociais do hospital. Além disso, os vídeos foram disponibilizados nas mídias sociais semanalmente para que familiares também pudessem acompanhar e exibir aos internos, e tomados os devidos cuidados com a higienizaçáo dos dispositivos móveis.

Durante a pandemia, os palhaços também realizavam reuniôes virtuais mensais de estudos, a fim de consolidarem novas técnicas e aprofundarem os conhecimentos, cientes da responsabilidade exigida. Tal consolidação do saber é fundamental para os desafios diários, uma vez que pode haver resistência por parte dos hospitalizados ou mesmo pelos profissionais de saúde.

Tal reestruturação é sintetizada como um processo de grande aprendizado, principalmente para o grupo de voluntários. Aprender a lidar com a câmera, interagir com um aparelho eletrônico, ter seu espaço de atuação limitado a um enquadramento específico, além de não presenciar o riso do seu público certamente traduzem uma realidade totalmente nova, mas necessária para a segurança e o bem- estar daqueles que estáo restritos ao ambiente hospitalar.

Embora os meios tenham sido alterados, os fins continuam em sincronia com os resultados pré-pandemia: é possível perceber a satisfação com a figura do palhaço8. Estes amenizam a tristeza e a solidão, tornam-se fonte de apoio, encorajam o enfrentamento da doença e dáo suporte emocional aos pacientes. As atividades lúdicas são responsáveis por melhorias na adaptação e na recuperação, além de serem capazes de reinserir o pensamento positivo em relação ao desfecho particular'. Influem lembranças passadas, alusóes à infância e tempos de mocidade em que não existia uma doença estabelecida, uma preocupação com o amanhã ou mesmo a solidão de um leito hospitalar. Quebram com o contexto atual, proporcionam uma digressáo construtiva para o enfermo, descaracterizam o estado emocional negativista ${ }^{10}$. Assim, os palhaços auxiliam na complementação do cuidado integral, envolvendo as dimensôes biopsicossociais e superando a fragmentação da abordagem hospitalar.
A satisfação com o projeto não se limita apenas ao paciente oncológico, mas atinge também familiares e amigos. Os acompanhantes aceitam positivamente as açôes, enxergando nelas um pensamento ético, holístico, social e humanitário ${ }^{11}$. As ações reparadoras distraem os familiares e os amigos, abrindo espaço para desabafarem e receberem conforto dos palhaços ${ }^{12}$.

Os profissionais de saúde (médicos, enfermeiros, cirurgiôes-dentistas, fisioterapeutas, técnicos, entre outros) também são contemplados com ânimo, melhores interaçôes na equipe multiprofissional e reduçáo do estresse em um ambiente carregado de tensão e angústia ${ }^{13}$. Reforçam a visão do cuidado integral, despertam a importância de colocar em prática valores humanistas e construir vivências. Desenvolve-se um olhar refinado, atento às necessidades que vão além de diagnósticos clínicos, incentivando a ética da alegria na atuação do profissional.

E assim a fonte de todo o riso também é renovada, reverberando a satisfação até mesmo nos palhaços voluntários que, para além de suas profissóes cotidianas, reservam um período de suas semanas para transformarem positivamente o entorno hospitalizado do próximo. A terapia do riso se transforma em terapia do amor, eficiente para ambos os lados: aquele que sorri e aquele que recebe o sorriso sincero. Sintetizar todo o trabalho desses voluntários apenas em humor seria uma análise superficial. Eles carregam compaixão, humildade, empatia e envolvimento ${ }^{14}$. Os palhaços são valorizados e suas atuaçóes ganham espaço, mesmo em um contexto pandêmico caótico, reconhecidos pela sociedade em geral e também pela comunidade científica, que já consegue comprovar o quão benéfico é para o reestabelecimento da saúde do hospitalizado essa interação lúdica, um exemplo nítido da função social e da promoção à saúde atrelados à $\operatorname{arte}^{15}$. O trabalho lúdico engrandece a formação holística do palhaço, propiciando vivências únicas e contribuindo para o aprimoramento das técnicas de comunicação ${ }^{16}$. Embora seja uma atuação descontraída e cheia de improvisos, os palhaços desenvolvem um trabalho com seriedade, profissionalismo e confiança.

Entretanto, a presença do palhaço pode ser vista como inconveniente, desdobrando-se em insegurança e em bloqueio à proposta lúdica. Existem contextos em que profissionais terciários não são favoráveis às atividades, como durante procedimentos ${ }^{17}$, e pequenas parcelas de entrevistados alegam que os projetos de humor não são eficazes, com a justificativa de que existam pacientes que não se identificam com os palhaços e também pacientes profundamente imersos na doença que não conseguem se envolver com as brincadeiras ${ }^{8}$. Em virtude disso, os palhaços se especializam dia após dia para terem bagagem técnica suficiente e lidarem com tais situaçóes. 
Especificamente no contexto dos Especialistas da Alegria, não existiam tais conflitos durante o caráter presencial do projeto, os voluntários já estavam estabelecidos no hospital há anos, havia uma forte relação com as equipes de enfermagem que os direcionavam para casos mais específicos, evitando possíveis problemas. Os palhaços sempre estavam atentos com relaçáo ao barulho e analisavam o contexto geral para não fugirem do objetivo do projeto.

\section{CONCLUSÃO}

A atuação de palhaços em ambiente hospitalar de atençáo oncológica apresenta resultados positivos que refletem a vasta gama de benefícios da ludoterapia no ambiente hospitalar, revelando a conquista dos objetivos propostos inicialmente pelos voluntários. A palhaçaria possibilita melhorias para o enfermo, sejam físicas, psicológicas ou emocionais. Acompanhantes, familiares e amigos são acolhidos e possuem a chance de externalizar as angústias trazidas pela enfermidade. Além disso, as doses de humor reagem positivamente nos profissionais de saúde, que as recebem com abertura e gratidão, refletindo maior interaçáo entre as equipes multiprofissionais e satisfação pelos serviços prestados. Juntamente com os palhaços, os profissionais da saúde atuam com humanização e integralidade do cuidado.

Embora a pandemia da covid-19 tenha restringido as atividades lúdicas presenciais, os Especialistas da Alegria conseguiram contornar o isolamento físico por intermédio dos meios digitais. $\mathrm{Na}$ Era da informação, nada melhor do que usar os avanços tecnológicos para proporcionar bem-estar e qualidade de vida para todos os envolvidos, sejam eles espectadores, figurantes ou artífices na arte de sorrir.

\section{CONTRIBUIÇÕES}

Os autores contribuíram igualmente em todas as etapas do manuscrito e aprovaram a versão final a ser publicada.

\section{DECLARAÇÃO DE CONFLITO DE INTERESSES}

Nada a declarar.

\section{FONTES DE FINANCIAMENTO}

Não há.

\section{REFERÊNCIAS}

1. Macena CS, Lange ESN. A incidência de estresse em pacientes hospitalizados. Psicol Hosp. 2008;6(2):20-39.
2. Scannavino CSS, Sorato DB, Lima MP, et al. PsicoOncologia: atuação do psicólogo no Hospital de Câncer de Barretos. Psicol USP. 2013;24(1):35-53. doi: https:// doi.org/10.1590/S0103-65642013000100003

3. Araújo TCCF, Guimarães TB. Interações entre voluntários e usuários em onco-hematologia pediátrica: um estudo sobre os "palhaços-doutores". Estud Pesqui Psicol. 2009;9(3):632-47. doi: https://doi.org/10.12957/ epp.2009.9072

4. Pekelman R, Ferrugem D, Minuzzo FAO, et al. A arte de acolher através da visita da alegria. Rev APS. 2009;12(4):510-6.

5. Rodrigues AFA, Nunes Filho WJ. A utilização do palhaço no ambiente hospitalar. OuvirOUver. 2014;9(1):72-81. doi: https://doi.org/10.14393/OUV11-v9n1a2013-6

6. Especialista da Alegria [Internet]. Curitiba, PR: Ministério do Turismo; [acesso 2020 jun 22]. Disponível em: https://especialistasdaalegria.com.br/

7. Straub A, editor. Relatório Anual 2019 [Internet]. Curitiba: Erasto Gaertner; 2019 mar [acesso 2020 out. 13]. Disponível em: https://erastogaertner.com.br/ arquivos/relatorio2019/RA_2019-2020_WEB.pdf

8. Dantas FRA, Ferreira LDO, Da Silva KAW, et al. A contribuição do lazer no processo de hospitalizaçáo: um estudo de caso sobre os benefícios do projeto risoterapia. LICERE. 2014;17(2):53-85. doi: https:// doi.org/10.35699/1981-3171.2014.849

9. Moura CC, Resck ZMR, Dázio EMR. Atividades lúdicas realizadas com pacientes portadores de neoplasia internados em hospital geral. Rev Rene. 2012;13(3):667-76.

10. Catapan SC, Oliveira WF, Rotta TM. Palhaçoterapia em ambiente hospitalar: uma revisão de literatura. Ciênc Saúde Colet. 2019;24(9):3417-29. doi: https://doi. org/10.1590/1413-81232018249.22832017

11. Fraquinello P, Higarashi IH, Marcon SS. O atendimento humanizado em unidade pediátrica: percepção do acompanhante da criança hospitalizada. Texto Contexto Enferm. 2007;16(4):609-16. doi: https://doi. org/10.1590/S0104-07072007000400004

12. Amorim KPC, Rocha AKC, Silva ICS. Mediarte com amor e humor: uma experiência a partir do olhar dos participantes. Rev Bras Educ Med. 2015;39(2):294-301. doi: https://doi.org/10.1590/1981$52712015 \mathrm{v} 39 \mathrm{n} 2 \mathrm{e} 01132014$

13. Oliveira CS, Okubo CVC, Ribeiro RP, et al. Palhaço de hospital: percepçóes do profissional da enfermagem de uma unidade pediátrica. Ciênc Cuid Saúde. 2017;16(3). doi: https://doi.org/10.4025/cienccuidsaude.v16i3.34924

14. Luchesi A, Cardoso FS. Terapia do riso: um relato de experiência. Rev Eletrôn Fac Evang Paraná. 2012;2(1):11-20.

15. Espinosa BB, Gutiérrez TR. Lo esencial es invisible a los ojos: payasos que humanizan y promueven salud. Aletheia. 2010 jan-abr;31:4-15. Espanhol. 
16. Paiva MLF, Oliveira ASB, Lima FMLS. Pronto sorriso: ferramenta metodológica inovadora de ensino-aprendizagem. In: Nilcee MSCC, Edna RSP, organizadores. Pronto sorriso: ferramenta metodologica inovadora de ensino-aprendizagem. Vol. 1. Goiânia: CAPES; 2015. p. 57-70.

17. Vagnoli L, Caprilli S, Robiglio A, et al. Clown doctors as a treatment for preoperative anxiety in children: a randomized, prospective study. Pediatrics. 2005;116(4):e563-7. doi: https://doi.org/10.1542/ peds.2005-0466 